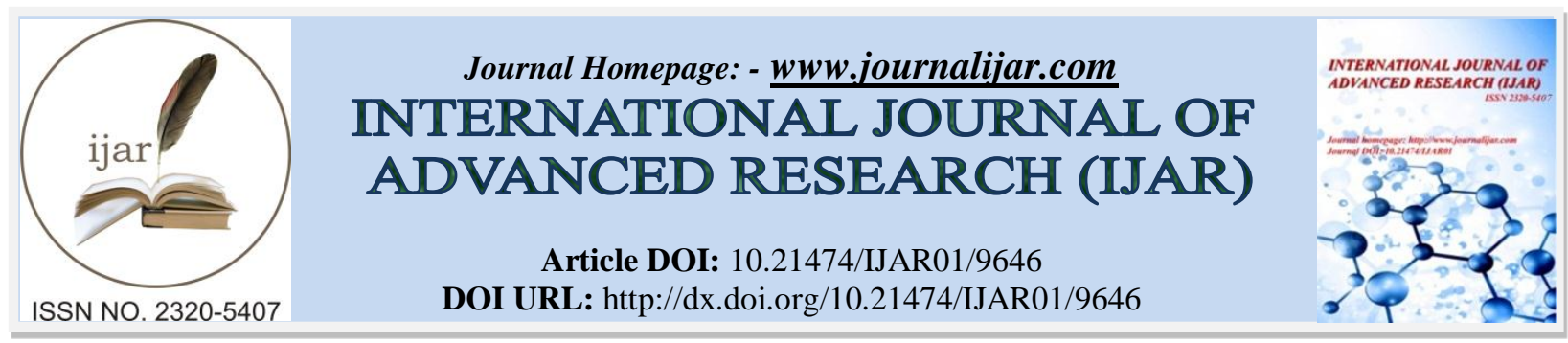

RESEARCH ARTICLE

\title{
STUDY ON CHARACTERISTICS OF PARTICULATE MATTER EMISSION FROM SEVERAL BURNING ACTIVITIES IN OUR DAILY LIVES.
}

Ning Zhang, Na Li, Wei-Shuai Dai, Yuan-Yuan Li, Ye-shun Peng, Peng Wang and Ting Guo.

College of Geography and Environmental Sciences, Zhejiang Normal University, Jinhua 321000, China.

\section{Manuscript Info}

Manuscript History

Received: 04 July 2019

Final Accepted: 06 August 2019

Published: September 2019

Key words:-

Particulate Matter; Indoor combustion;

Carrier component characterization;

Cigarettes; Sandalwood; Mosquito coils.

\begin{abstract}
Much evidence suggested that indoor combustion could cause a significant increase in the concentration of fine Particulate Matter (PM) in indoor air and it is an important cause of indoor pollution. In this paper, the characteristics of PM emission from several burning activities in daily lives were studied in a transparent bottomless chamber covered with teflon filter. The particle size distribution and the chemical composition loaded on the PM generated during the burning of cigarettes, sandalwood, mosquito coils and candles were analyzed and the results were discussed and compared with those of conventional combustion sources such as coal and oil. The finer particles(less than $1 \mu \mathrm{m}$ ) were released from combustion sources in our daily lives compared with that of traditional dust from coal and oil. A large amount of $\mathrm{Pd}, \mathrm{Cr}$ and $\mathrm{Cd}$ were detected loaded on the sandalwood dust, mosquito dust and cigarette dust, which were also different with the traditional industrial coal dust and oil dust and indicated a higher health risk. Almost all carbon loaded on the PM by burning cigarette or candle were OC, and the OC content loaded on the PM by burning Sandalwood and mosquito coil accounted for $96 \%$ and $98 \%$ of total carbon respectively. $\mathrm{SO}_{4}{ }^{2-}$ was the most abundant inorganic ion regardless of which material was burned and there were a lot of $\mathrm{F}^{-}$ loaded on the sandalwood dust and mosquito dust which should be pay more attention since $\mathrm{F}^{-}$is always associated with many health effects.
\end{abstract}

Copy Right, IJAR, 2019,. All rights reserved.

\section{Introduction:-}

Particulate matter (PM) was globally recognized as a major environmental issue because of its strong influence on the climate system, regional visibility and human health (Tian et al., 2017). The World Health Organization (WHO) reported that in 2012 around 7 millions of people died as a result of air pollution exposure (Tian et al., 2017). Exposure to PM has been an issue of great concern for public health, because some scientific researchers found that a close association between an increase in the levels of airborne fine and ultra-fine particles (UFPs $<100 \mathrm{~nm})$ and an increase in morbidity and mortality rates (WHO, 2013). PM has been linked to many adverse effects on human health, such as major cardiovascular effects (acute myocardial infarction, ischemic stroke, hemorrhagic stroke, or death due to cardiovascular effects) (Noh et al., 2016) and respiratory disorders (lung inflammation, asthma, and brosis) (Manigrassoet al., 2017). PM was also considered as a major environmental risk factor for several neurodegenerative diseases, because it played an important role in their pathogenesis and pathophysiology (Heusinkveld et al., 2016). The International Agency for Research on Cancer (IARC) had classed PM as a group 1 
carcinogen to humans (IARC,2015). Most of the negative impacts on human health have been related to $\mathrm{PM}_{10}$ and $\mathrm{PM}_{2.5}$. It is essential to identify the physical and chemical properties and sources of PM, but it has remained a largely complex subject of study due to it's complex nature (Palmaet al., 2017). Burning is a significant cause of atmospheric particulate matter pollution. Combustion does not only directly release copious amount of primary particles, but also emits a lot of volatile and/or semi-volatile substances which would likely condense or react with other chemically active substances to produce secondary organic aerosol (SOA) once they enter into the atmosphere.

Coal or fuel associated with industrial production, motor vehicle exhaust and straw has been recognized as the main sources of air pollution. In addition to these traditional combustion sources, there are many combustion related activities in our daily lives that could also produce PM. Among these, smoking is the most common activity. Though it is widely recognized as the main cause of lung cancer events (American Cancer Society, 2014), the number of smokers continues to increase every year. In fact, about $60 \%-90 \%$ of lung cancer events for women/men were related to cigarette smoking (Stabileet al., 2017). As a key factor affecting the human health, most of the study about environmental tobacco smoke (ETS) focuses on the impact of ETS on human health from the medical perspective, only a few have focused on the characteristics of ETS such as its composition, particle size distribution and contents carried on the PM (Johnsonet al., 2015).

In Asia and other countries throughout the world, such as the United States, many countries have the habit of burning sandalwood and mosquito coils in the room. Mosquito coils usually contain active ingredients such as allethrin, beclomethasone or propimathrin, which would be released to prevent humans from mosquito bites or mosquito-borne diseases in their smoldering process. Sandalwood also contains a large number of additives and individuals like to burn sandalwood in rooms since it creates exceptional aromas. In the past, candles were widely used throughout the world as a lighting material. Today, although lamps have replaced candles as a cheaper and more convenient lighting tool, candles are still used in some religious activities or burned for creating a cozy atmosphere in middle or high income countries. Li and Ro et al. (1998) found that the indoor polycyclic aromatic hydrocarbons (PAHs) level was higher than their outdoor level and proposed this result was related to indoor combustion behaviors. Some studies were carried out by the burning of mosquito coil and reported the toxicological effects of mosquito coil smoke (Zhang et al., 2010; Li et al., 2016; Yang et al., 2015; Liu et al., 2003). There was few scientific studies on the characteristics of PM emitted from these combustion activities because all these burning activities belong to personal behavioral habits and occur privately.

Indoor combustion could cause a significant increase in the concentration of fine PM in indoor air and it is an important cause of indoor pollution (Manigrasso et al., 2017; Stabile et al., 2014; Chen et al., 2015; Slezakova et al., 2011; Roberts et al., 2017). As people stay indoors longer than outdoors, the indoor air quality may be more important to the health of the population (Chen et al., 2009). In this paper, the characteristics of PM emission from several burning activities in daily lives were studied in a transparent bottomless Plexiglas chamber, the particle size distribution and the chemical composition loaded on the PM generated during the burning processes were analyzed and the results were discussed and compared with those of conventional combustion sources such as coal and oil

\section{Methods and materials:- Experimental device}

This study was carried out in a transparent bottomless chamber covered with teflon filter and had several ventilation vents on the side of the chamber $\left(1 \times 1 \times 1 \mathrm{~m}^{3}\right)$. Anderson sampler (TISCH, Model TE-20-800) or atmospheric particulate sampler (Wuhan Tianhong Instrument Co. Ltd., model TH-150CIII) was placed at the middle of the experiment chamber. The burning materials were ignited first then placed on the small experimental benches which were placed in the four corners of the experimental chamber. Fresh air entered into the chamber through the air vents and the smoke generated during the combustion process flowed with the air into the sampler, then the target practical matter were collected by the sampling filter. It was necessary to supply sufficient air to ensure not only the completed combustion of the burning material but also the amount of air required for particle sampling. The experimental system was shown in Figure 1. 


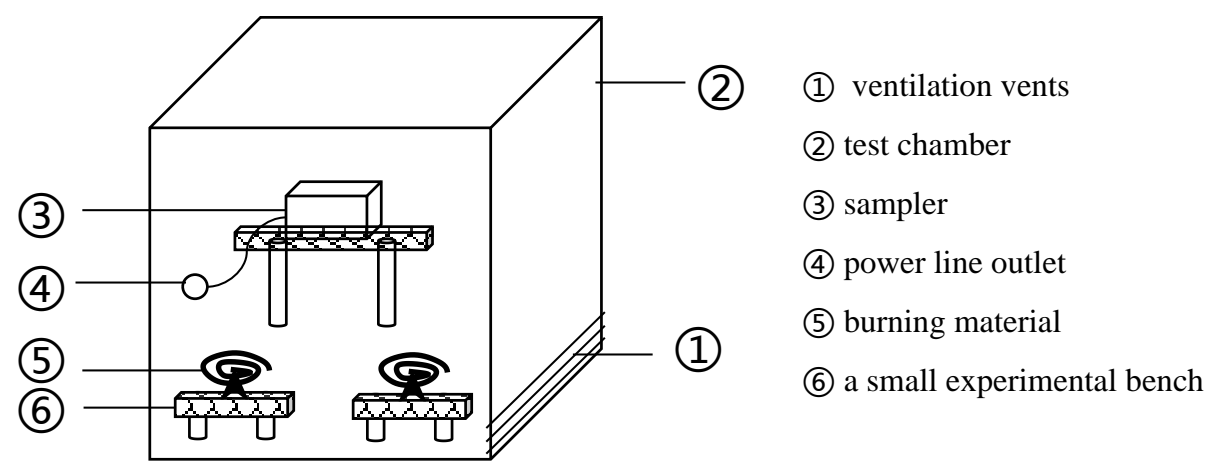

Fig 1:-A experimental setup diagram

\section{Experimental materials}

Glass fiber filters (Hao Chen Tiancheng company, diameter of 81nm, efficiency 99.995\%) were used in Andersen samplers for the analysis of the size distribution of dust combustion, while Quartz filters (Hao Chen Tiancheng company, diameter $90 \mathrm{~nm}$, efficiency $99.995 \%$ ) were used in atmospheric $\mathrm{PM}_{2.5}$ sampler for the analysis of elements and inorganic water-soluble ions.

Mosquito coil (Punctuality Brand, Shanghai SC Johnson Ltd.) used in this study was traditional types of mosquito coils ejecting smoke. The sandalwood (My Taste, Shanghai Fen Bo Industrial Co. Ltd.) was also an ordinary household sandalwood with lavender scent. The cigarettes (Really Dragon, Guangxi Tobacco Industry Co. Ltd.) were flue-cured cigarettes, and each cigarette contained $11 \mathrm{mg}$ tar and $1.1 \mathrm{mg}$ nicotine. The candles (Bright Candles, Zhejiang De Jing Candle Factory) were white candles for general lighting. All the burning materials (mosquito coil, Sandalwood, cigarette, and candle) were purchased from the supermarket.

\section{Sampling process}

Filters were put into the sampler. Adjustment of the sample flow was made based on the sampler's requirements. The flow of sampler was $28 \mathrm{~L} / \mathrm{min}$ for Andersen samplers, while the flow of sampler was $100 \mathrm{~L} / \mathrm{min}$ for the atmospheric $\mathrm{PM}_{2.5}$ sampler. Burning material were ignited then placed in the chamber at the correct location according to the schematic diagram of the experimental system (Fig. 1). The sampler was startedwhen the burning smoke had filled with the chamber, then sampling 5 minutes.

\section{Sample analysis}

Weighing

The filters were weighed with a precision balance (model AUW-120D) which was manufactured by Shimadzu Corporation. Weighing the weight of each filter before sampling and after sampling respectively, the PM count of the sampling was obtained by calculating the weight difference.

\section{Analysis of OC/EC}

In this study, OC/EC loaded on the PM were analyzed using the thermal carbon analyzer of Model 2001 (Thermal/Optical Carbon Analyzer) produced by American Desert Research Institute. The contents of OC and EC in the particulate samples were measured, which according to the hot light reflection method (TOR) specified by the Interagency Monitoring Of Protected Visual Environment (IMPROVE) analysis protocol. This method was a recommended method for the actual measurement of OC and EC in the atmosphere (Viiet al., 2015).

\section{Elemental Analysis}

21 kinds of elements loaded on the PM were analyzed using the ICP-MS. ICP-MS was an analytical instrument that combines ICP technology with mass spectrometry. These 21 elements were $\mathrm{Na}, \mathrm{Mg}, \mathrm{Al}, \mathrm{K}, \mathrm{Ca}, \mathrm{Ti}, \mathrm{V}, \mathrm{Cr}, \mathrm{Mn}, \mathrm{Fe}$, $\mathrm{Co}, \mathrm{Ni}, \mathrm{Cu}, \mathrm{Zn}, \mathrm{As}, \mathrm{Se}, \mathrm{Pd}, \mathrm{Ag}, \mathrm{Cd}, \mathrm{Ba}$, and $\mathrm{Hg}$, which included the majority of single metal elements.

\section{Ion analysis}

Four anions $\left(\mathrm{SO}_{4}{ }^{2-}, \mathrm{NO}_{3}^{-}, \mathrm{F}^{-}\right.$, and $\left.\mathrm{Cl}^{-}\right)$loaded on the PM samples were quantitatively analyzed by $\mathrm{DX}-120$ ion chromatography manufactured by DIONEX Company. A $1 / 8$ piece of quartz fiber filter was put into a glass tube and deionized extracted using water. The extraction procedure was conducted for at least three times so that the water soluble ions of samples were extracted adequately into the solution. 


\section{QA/QC}

All experimental quartz filter were baked into the muffle furnace at about $500^{\circ} \mathrm{C}$ (glass fiber filter heating temperature was $400^{\circ} \mathrm{C}$ ) for 2 hours before sampling in order to remove volatile components and other components of the filters.

The blank or sample filters were placed into the balance room for 24 hours, then weighted. Filter were weighed 3 times using discontinuous methods, and the average represented the weight of the filter. The temperature of the balance room should be maintained at one point $\left( \pm 0.5^{\circ} \mathrm{C}\right)$ between $15 \sim 35^{\circ} \mathrm{C}$, relative humidity be maintained less than $50 \%$.

The Anderson sampler was checked and cleaned after each sampling work to avoid blockage of the vent holes.

The first sample was re-analyzed every ten samples and the precision was expected to be less than $2 \%$. The calibration of the analyzer should be done before and after sample analysis every day.

For analysis of the elements and ions, standard reference materials were pre-treated and analyzed using the same procedure, with the recovered values for all the target elements falling into the range or within 5\% of certified values.

All filters should be weighed and analyzed as soon as possible after they had been sampled. If the sampling filter could not be analyzed in time, kept the filter in $4^{\circ} \mathrm{C}$ refrigerator, but the storage time should not exceed 15 days.

\section{Results and discussion:-}

\section{Particle size distribution}

It is well known that the size distribution of particulate matter (PM) determines the potential effects for human health (Slezakova et al., 2011). Furthermore, many toxicological studies found that ultrafine and nanoparticles contained much more trace of toxic substances ( $\mathrm{As}, \mathrm{Se}, \mathrm{Pb}, \mathrm{Cr}$, etc.) and organic pollutants (PAHs, PCDDPFs, etc.) than fine and coarse PM (Li et al., 2014).
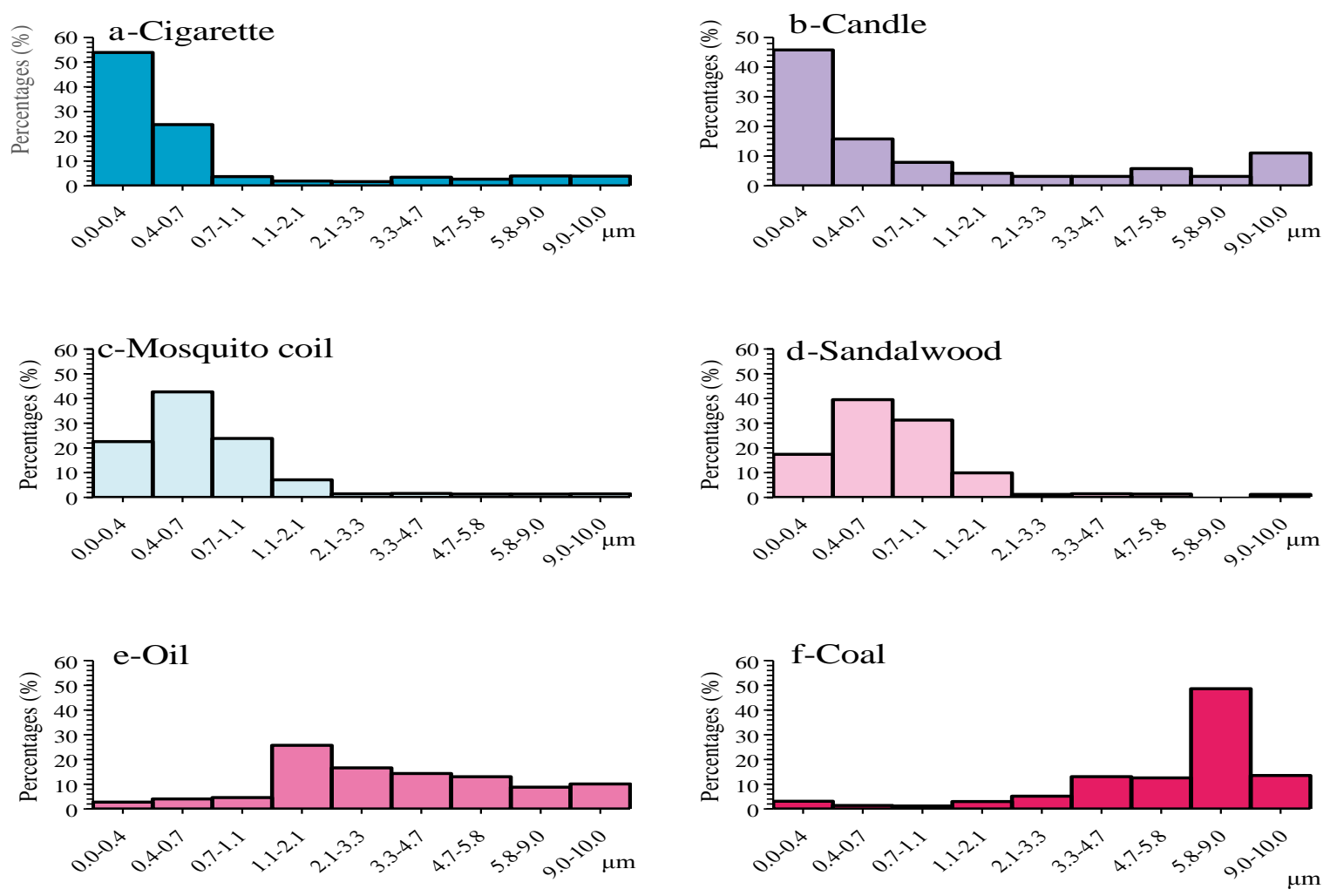

Fig 2:-The particle size distribution of the PM produced by the combustion sources 
Combustion is the main source of fine PM in the atmosphere, especially for finer PM, and the emission characteristics of PM were different because of burning different materials. The results of the particle size distributions of PM produced by burning mosquito coil, sandalwood, cigarette, candle, coal (Zhu et al., 1995), and oil (Zhou et al., 2012) were shown in Figure 2. The PM produced by burning cigarette and candle were mostly concentrated in the range of $0.0-0.4 \mu \mathrm{m}$, the PM produced by the burning of mosquito coil and sandalwood were mostly concentrated in the range of $0.4-0.7 \mu \mathrm{m}$, while the PM produced by burning oil and coal were mostly concentrated in the range of $1.1-2.1 \mu \mathrm{m}$ and 5.8-9.0 $\mu \mathrm{m}$ respectively. Figure 3 showed the results of the median diameters of the PM corresponding of each burning scene. It could be found that the finer particles (less than $1 \mu \mathrm{m}$ ) were released from combustion sources in our daily lives compared with that of traditional dust from coal and oil. The largest median diameter was of coal dust measuring at $6.57 \mu \mathrm{m}$, while the smallest was that of the cigarette dust measuring at $0.37 \mu \mathrm{m}$. The order of the median particle sizes were as follows: cigarette $<$ candle $<$ mosquito coil< sandalwood $<$ oil $<$ coal.

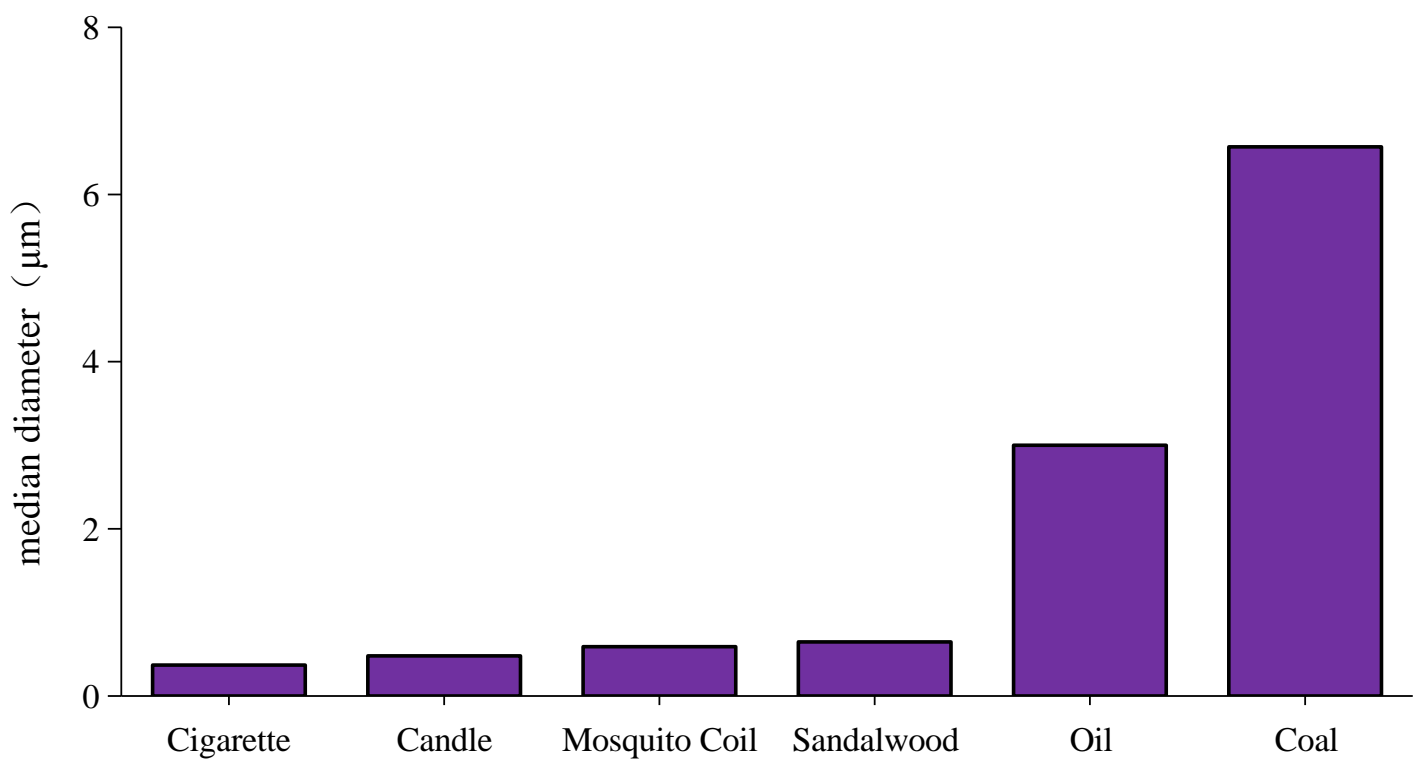

Fig 3:-The results of the median diameters of the PM of different combustion sources 


\section{Elemental analysis}

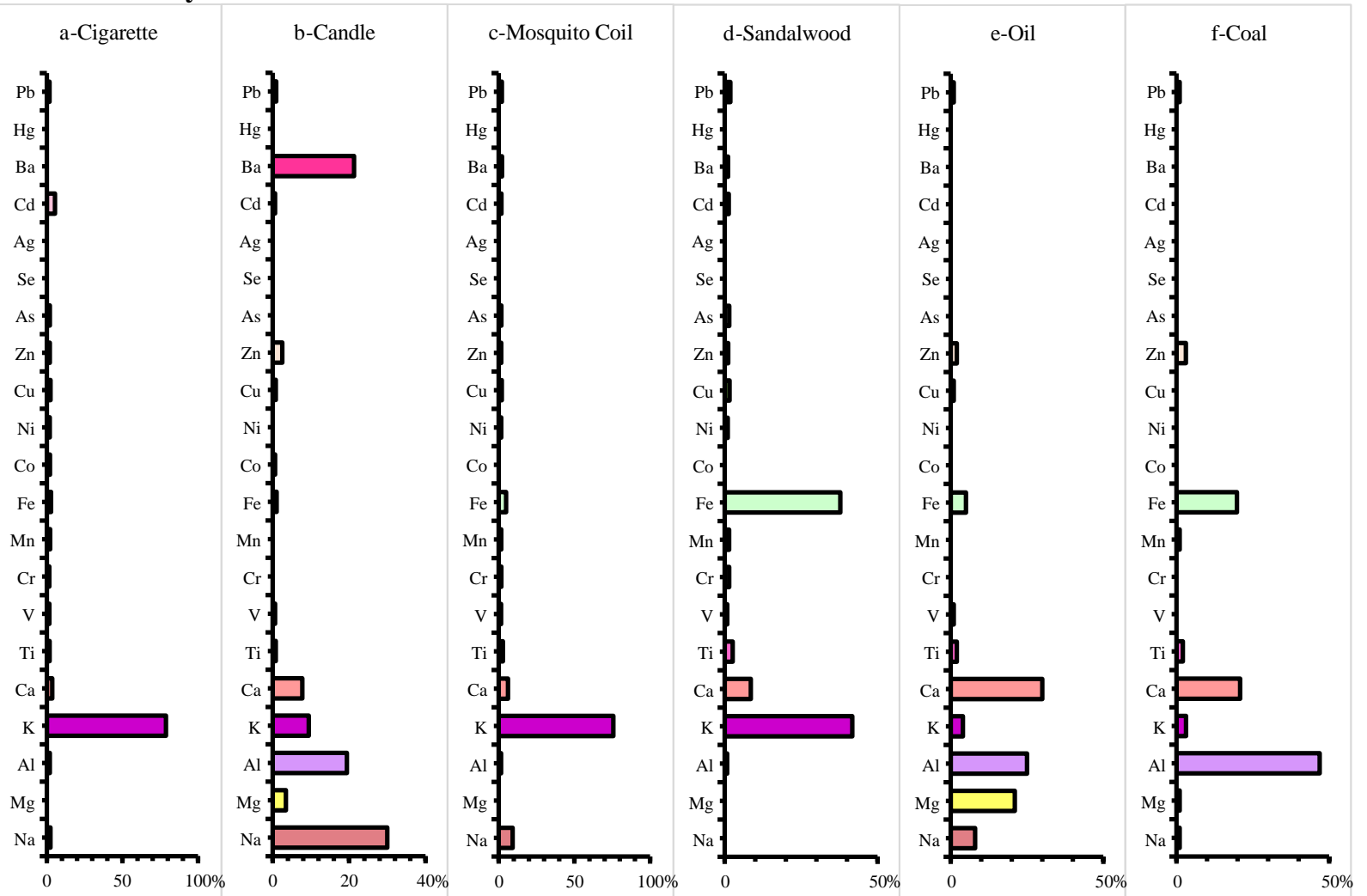

Fig 4:-Element spectrum of PM produced by each combustion source.

The distribution results of elements carried on the PM generated during the combustion of different kinds of materials were shown in Figure 4. Unlike traditional industrial coal dust (Zhu et al., 1995) and oil dust (Zhou et al., 2012), the elements carried on the PM that were released from the combustion sources of our daily lives had their own distinctive characteristics. $\mathrm{Ca}, \mathrm{Al}, \mathrm{Mg}$ and $\mathrm{Fe}$ were the most abundant elements carried by coal and oil dust, but $\mathrm{Na}$ and $\mathrm{Ba}$ were the most abundant elements carried by candle dust. It was well known that $\mathrm{K}$ was a representative element of biomass combustion. Similar to straw burning dust (Li et al., 2006), K was also the most abundant element carried by cigarette dust, sandalwood dust and mosquito dust, but more heavy metal elements, such as Pd, $\mathrm{Cd}$ and $\mathrm{Cr}$, were detected loaded on the sandalwood dust, mosquito dust and cigarette dust compared to straw dust, and the same results were obtained for coal dust and oil dust also. The contents of heavy metal elements loaded on the PM were listed in Table 1. In 2003, the U.S. Agency for Poisons and Diseases (ATSDR) listed the elements causing cancer in humans or animals, they were $\mathrm{Cr}, \mathrm{Ni}, \mathrm{As}, \mathrm{Cd}, \mathrm{Pb}, \mathrm{Be}, \mathrm{Co}$ and $\mathrm{Hg}$ (Slezakova et al., 2011). Compared to burning coal and oil, some indoor combustion behavior, such as smoking cigarettes, smoldering sandalwood and mosquito coils might have a higher health risk because much of $\mathrm{Pb}$ and $\mathrm{Cd}$ were loaded on their dust.

Table 1:-The contents of heavy metal elements loaded on the PM released from different combustion source.

\begin{tabular}{|c|c|c|c|c|}
\hline Combustion Source & $\mathrm{Cd}(\%)$ & $\mathrm{Cr}(\%)$ & $\mathrm{Pb}(\%)$ & $\mathrm{As}(\%)$ \\
\hline Cigarette & 2.89 & 0.02 & 0.95 & 0.21 \\
\hline Candle & 0.00 & 0.00 & 0.30 & 0.00 \\
\hline Mosquito Coil & 0.23 & 0.18 & 0.53 & 0.20 \\
\hline Sandalwood & 0.55 & 0.69 & 1.85 & 0.71 \\
\hline Oil & 0.00 & 0.19 & 0.47 & 0.01 \\
\hline Coal & 0.00 & 0.11 & 0.45 & 0.06 \\
\hline Straw & 0.00 & 0.08 & 0.17 & 0.08 \\
\hline
\end{tabular}




\section{OC/EC}

Carbonaceous particles produced from combustion were generally divided into three fractions: (a) organic carbon (OC); (b) elemental carbon (EC), also called black carbon (BC) or soot (Sanchez et al., 2009); and (c) carbonate carbon (CC) (Schauer et al., 2003). In urban areas, CC usually represents only $1 \%$ of the fine fraction and between $2 \%$ and $3 \%$ of the coarse fraction (Elżbieta et al., 2016). Since the CC content was always very low, only OC and EC content were analyzed in this study.

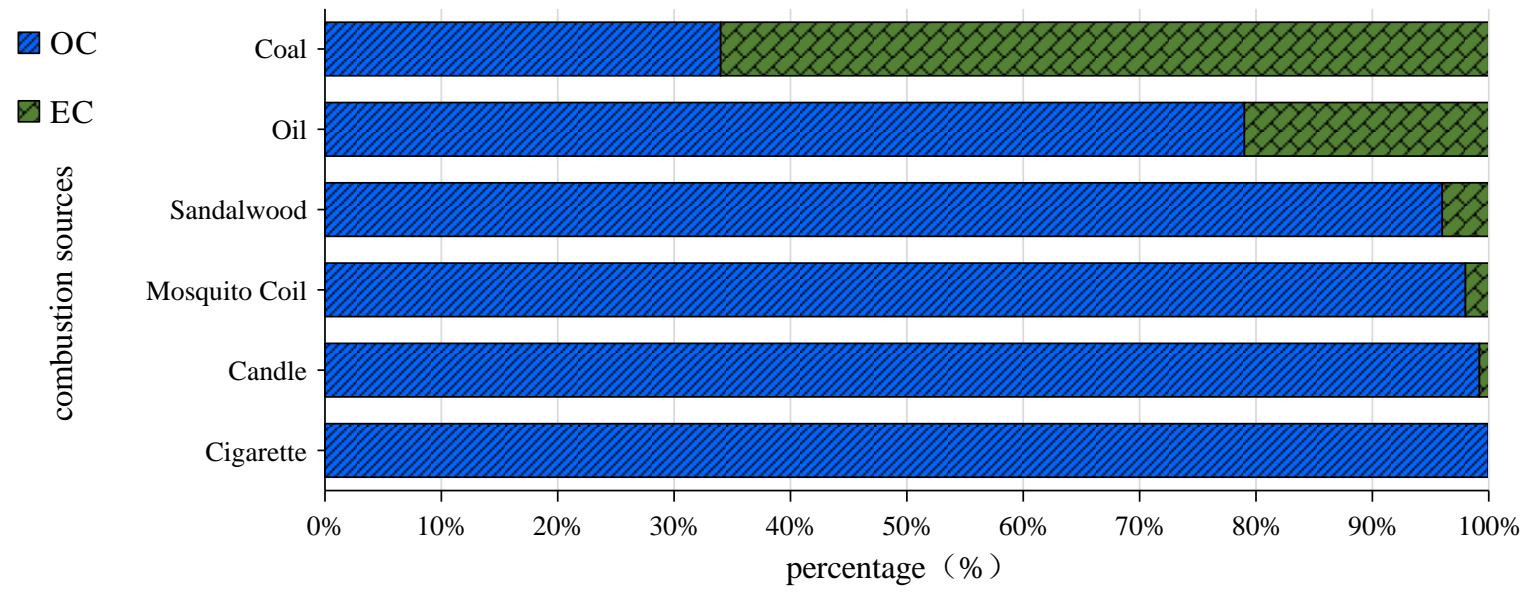

Fig 5:-The ratio of OC and EC on the PM produced by different combustion sources.

The distribution spectrum of OC and EC loaded on PM generated by different combustion source were analyzed and the analysis results were shown in Figure 5. Compared with particles released from these traditional combustion sources PM released from the combustion sources used in our daily lives carried more OC. The OC content loaded on coal dust (Zhu et al., 1995) and oil dust (Zhou et al., 2012) accounted for about $66 \%$ and $79 \%$ of total carbon respectively. While, the carbon loaded on the PM by burning cigarette and candle were almost all OC and the OC content accounted for greater than $99 \%$ of total carbon. The OC content loaded on the PM by burning Sandalwood and mosquito coil accounted for $96 \%$ and $98 \%$ of total carbon respectively, and all these values were greater than 95\%. OC contained more carcinogenic and mutagenic compounds ( $\mathrm{Li}$ et al., 2014). Therefore, indoor combustion sources should receive more attention than traditional combustion sources because the particulate matter released from indoor combustion it contained more OC, which indicated greater health and environmental risks.

\section{Inorganic ion analysis}

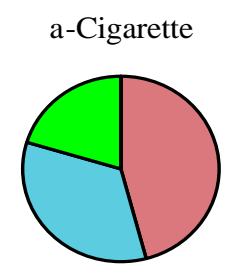

d-Sandalwood

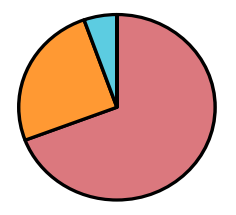

$\mathrm{F}^{-}$

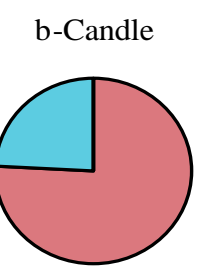

e-Oil

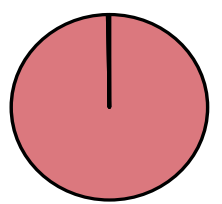

$\mathrm{Cl}^{-}$

$\mathrm{NO}_{3}{ }^{-}$

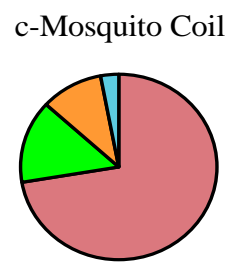

f-Coal

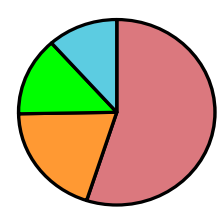

$\mathrm{SO}_{4}{ }^{2-}$

Fig 6:-The distribution results of inorganic ion components carried on the PM generated during the combustion of four kinds of materials 
Several studies had shown that the presence of charge on particles may increase the deposition rate in the lungs. Cohen's research showed that when particles carried charges, the deposition rate of particles in the lungs increased 3-5 times (Stabile et al., 2014). Figure 6 showed the distribution results of inorganic ion components carried on the PM generated during the combustion of four kinds of materials. Only three types of inorganic ions were detected from the cigarette dust, they were $\mathrm{SO}_{4}{ }^{2-}, \mathrm{NO}_{3}{ }^{-}$and $\mathrm{Cl}^{-}$, and the contents of those ions were $45.86 \%, 33.78 \%$ and $20.36 \%$, respectively. Only two types of inorganic ions were detected from the candle dust, they were $\mathrm{SO}_{4}{ }^{2-}$ and $\mathrm{NO}_{3}{ }^{-}$, and the contents of those ions were $75.83 \%$ and $24.17 \%$, respectively. Four kinds of inorganic ions were detected on the mosquito dust and the proportion of $\mathrm{SO}_{4}{ }^{2-}$ accounted for $72.35 \%$, while the value of $\mathrm{Cl}^{-}, \mathrm{F}^{-}$and $\mathrm{NO}_{3}{ }^{-}$ were $14.40 \%, 10.27 \%$ and $2.97 \%$, respectively. Three kinds of inorganic ions were detected on the sandalwood dust and the proportion of $\mathrm{SO}_{4}{ }^{2-}, \mathrm{F}^{-}$and $\mathrm{NO}_{3}{ }^{-}$accounted for $69.23 \%, 25.34 \%$ and $5.43 \%$, and no $\mathrm{Cl}^{-}$were detected. For the coal dust (Zhu et al., 1995), the content of $\mathrm{SO}_{4}{ }^{2-}$ accounted for half, the content of $\mathrm{F}^{-}, \mathrm{Cl}^{-}, \mathrm{NO}_{3}{ }^{-}$were more than $10 \%$. For the oil dust (Zhou et al., 2012), there were almost all of $\mathrm{SO}_{4}{ }^{2-}$, only a very small amount of $\mathrm{Cl}^{-}$and $\mathrm{NO}_{3}^{-}$. Compared these six types of combustion sources, it can be found that $\mathrm{SO}_{4}{ }^{2-}$ was the most abundant inorganic ion regardless of which material was burned and there were a lot of $\mathrm{F}^{-}$loaded on the sandalwood dust and mosquito dust which should be pay more attention since $\mathrm{F}^{-}$is always associated with many health effects (Das et al., 2017; Yu et al., 2018).

\section{Conclusions:-}

The finer particles (less than $1 \mu \mathrm{m}$ ) were released from combustion sources in our daily lives compared with that of traditional dust from coal and oil. The PM released from burning cigarette and candle were mostly concentrated in the range of $0.0-0.4 \mu \mathrm{m}$, and those PM released from burning mosquito coil and sandalwood were mostly concentrated in the range of $0.4-0.7 \mu \mathrm{m}$. Different with the traditional industrial coal dust and oil dust, a large amount of $\mathrm{Pd}, \mathrm{Cr}$ and $\mathrm{Cd}$ were detected loaded on the sandalwood dust, mosquito dust and cigarette dust, which indicated smoldering mosquito coils or sandalwood and smoking cigarettes might have a higher health risk. Almost all carbon loaded on the PM by burning cigarette or candle were OC, and the OC content loaded on the PM by burning sandalwood and mosquito coil accounted for $96 \%$ and $98 \%$ of total carbon respectively. $\mathrm{SO}_{4}{ }^{2-}$ was the most abundant inorganic ion regardless of which material was burned and there were a lot of $\mathrm{F}^{-}$loaded on the sandalwood dust and mosquito dust which should be pay more attention since $\mathrm{F}^{-}$is always associated with many health effects.

\section{Acknowledgments:-}

The data analysis of this project was supported by the National Research Center for Environmental Analysis and Measurement, Beijing 100029, China.

\section{References:-}

1. American Cancer Society, 2014. Cancer Facts \& Figures 2014.Atlanta G. A.Ashraf, M. W. (2012). Levels of heavy metals in popular cigarette brands and exposure to these metals via smoking. Scientic World Journal 2012, 729430. http://dx.doi.org/10.1100/2012/729430.

2. Bautista Vii, A. T., Pabroa, P. C. B., Santos, F. L., Quirit, L. L., Asis, J. L. B., Dy, M. A. K., Martinez, J. P. G., 2015. Intercomparison between NIOSH, IMPROVE_A, and EUSAAR_2 protocols: Finding an optimal thermal-optical protocol for Philippines OC/EC samples. Atmospheric Pollution Research, 6(2), 334-342.

3. Chen, H. W., Chunyu, C., Lin, H. T., 2009. Indoor air distribution of nitrogen dioxide and ozone in urban hospitals. Bulletin of Environmental Contamination \& Toxicology, 83(2), 147-50.

4. Chen, Y. J., Tian, C. G., Feng, Y. L., Zhi, G. R., Li, J., Zhang, G., 2015. Measurements of emission factors of $\mathrm{PM}_{2.5}$, OC, EC, and BC for household stoves of coal combustion in China. Atmospheric Environment, 109, 190-196.

5. Das, S., de Oliveira, L. M., da Silva, E., Liu, Y. G., Ma, L. Q., 2017. Fluoride concentrations in traditional and herbal teas: Health risk assessment. In Environmental Pollution, 231, 779-784.

6. Elżbieta, K., Monika, C., Anna, Z.,Maciej, G., 2016. OC/EC from PM $_{10}$ in the vicinity of Turów lignite open-pit mine (SW Poland): Carbon isotopic approach. Atmospheric Pollution Research, 7(1), 40-48.

7. Heusinkveld, H. J., Wahle, T., Campbell, A., Westerink, R.H., Tran, L., Johnston, H., Stone, V.,Cassee, F. R., Schins, R. P., 2016. Neurodegenerative and neurological disorders by small inhaled particles. Neurotoxicology, 19, 94-106.

8. IARC, 2015. Monographs on the Evaluation of Carcinogenic Risks to Humans. International Agency for Research on Cancer. Outdoor Air Pollution Volume 109. WHO Press, Lyon, France Available at: http://monographs.iarc.fr/ENG/Monographs/vol109/index.php (last accessed 24 November 2016). 
9. Johnson, T. J., Olfert, J. S., Yurteri, C. U., Cabot, R., McAughey, J., 2015. Hygroscopic effects on the mobility and mass of cigarette smoke particles. Journal of Aerosol Science, 86, 69-78.

10. Li, C. S., Yusun, R., 1998. Indoor characteristics of polycyclic aromatic hydrocarbons in the urban atmosphere of Taipei. Atmospheric Environment, 34(4), 611-620.

11. Li, H. Z., Lydy, M. J., You, J., 2016. Pyrethroids in indoor air during application of various mosquito repellents: Occurrence, dissipation and potential exposure risk. Chemosphere, 144, 2427-2435.

12. Li, X. L., Xu, Z., Guan, C., Huang, Z., 2014. Particle size distributions and OC, EC emissions from a diesel engine with the application of in-cylinder emission control strategies. Fuel, 121(121), $20-26$.

13. Li, X. H., Fan, Y., Feng, L. J., 2006. Chemical mass balance receptor model and its application in the analysis of atmospheric particulate matter. Journal of Ocean University of China (Natural Science Edition), (02), 225228.

14. Liu, W. L., Zhang, J. F., Jamal, H. H., Juliana, J., Zailina, H., Bernard, D. G., 2003. Mosquito coil emissions andhealth implications. Environmental Health Perspective, 111, 1454-1460.

15. Manigrasso, M., Vitali, M., Protano, C., Avino P., 2017. Temporal evolution of ultrafine particles and of alveolar deposited surface area from main indoor combustion and non-combustion sources in a model room. Science of the Total Environment, 598, 1015-1026.

16. Noh, J., Sohn, J., Cho, J., Kim, C., Shin, D.C., 2016. YIA 02-02 long-term effects of fine particulate matter exposures on major adverse cardiovascular events. Journal of Hypertension, 34 Suppl 1, e202.

17. Palma, A.D., Capozzi, F., Spagnuolo, V., Giordano, S., Adamo, P., 2017. Atmospheric particulate matter intercepted by moss-bags: Relations to mosstrace element uptake and land use. Chemosphere, 176, 361-368.

18. Roberts, C., Wagler, G., Carr, M. M., Environmental Tobacco Smoke: Public Perception of Risks of Exposing Children to Second-and Third-Hand Tobacco Smoke. Journal of Pediatric Health Care Official Publication of National Association of Pediatric Nurse Associates \& Practitioners, 2017, 31(1), e7.

19. Sánchez de la Campa, A.M., Pio, C., de la Rosa, J.D., Querol, X., Alastuey, A., González-Castanedo, Y., 2009. Characterization and origin of EC and OC particulate matternear the Don ana National Park (SW Spain). Environmental Research., 109, 671-681.

20. Schauer, J. J., Mader, B. T., Deminter, J. T., Heideman, G., Bae, M. S., Seinfeld, J. H., Flagan, R. C., Cary, R. A., Smith, D., Huebert, B. J., Bertram, T., Howell, S., Kline, J. T., Quinn, P., Bates, T., Turpin, B., Lim, H. J. , Yu, J. Z. , Yang, H., Keywood, M. D., 2003. ACE-Asia intercomparison of a thermal-optical method for the determination of particle-phase organic and elemental carbon. Environmental Science \& Technology, 37(5), 993.

21. Slezakova, K., Pires, J. C. M., Martins, F. G., Pereira, M. C., Alvim-Ferraz, M. C., 2011. Identification of tobacco smoke components in indoor breathable particles by SEM-EDS. Atmospheric Environment, 45(4), 863-872.

22. Stabile, L., Buonanno, G., Ficco, G., Scungio, M., 2017. Smokers' lung cancer risk related to the cigarettegenerated mainstream particles. Journal of Aerosol Science, 107, 41-54.

23. Stabile, L., Jayaratne, E. R., Buonanno, G., Morawska, L., 2014. Charged particles and cluster ions produced during cooking activities. Science of the Total Environment, s 497-498, $516 .$.

24. Tian, Y. Z., Chen, J. B., Zhang, L. L., Du, X., Wei, J. J., Fan, H., Xu, J., Wang, H. T., Guan, L., Shi, G. L., Feng, Y. C., 2017. Source profiles and contributions of biofuel combustion for $\mathrm{PM}_{2.5}, \mathrm{PM}_{10}$ and their compositions, in a city influenced by biofuel stoves. Chemosphere, 189, 255-264.

25. World Health Organization (WHO), 2013. Health Effects of Particulate Matter. Policy Implications for Countries in Eastern Europe, Caucasus and Central Asia. Regional Office for Europe of WHO, Copenhagen, Denmark.

26. Yang, T. T., Lin, S. T., Lin, T. S., Chung, H. Y., 2015. Characterization of polycyclic aromatic hydrocarbon emissions in the particulate and gas phase from smoldering mosquito coils containing various atomic hydrogen/carbon ratios. Science of the Total Environment, s 506-507(506-507C), 391-400.

27. Yu, Z. C., Xu, C. H., Yuan, K. K., Gan,X. Z., Feng, C., Wang, X. Q., Zhu, L. Y., Zhang, G. H., Xu. D., 2018. Characterization and adsorption mechanism of $\mathrm{ZrO}_{2}$ mesoporous fibers for health-hazardous fluoride removal. In Journal of Hazardous Materials, 346, 82-92.

28. Zhang, L., Jiang, Z., Tong, J., Wang, Z., Han, Z., Zhang, J., 2010. Using charcoal as base material reduces mosquito coil emissions of toxins. Indoor Air, 20, 176-84.

29. Zhou, F., Tan, G. B., Feng, Y. L., Gao, W., Zhou. Z., 2012. Online Flight Time Mass Spectrometer Analysis of Cigarette Smoke. Analytical Laboratory, 31(10), 31-34.

30. Zhu, T., Bai, Z. P., Chen, W., 1995. Analysis of Sources of Atmospheric Particulates in Qinhuangdao City. Journal of Environmental Science, (05), 49-55. 